\title{
Lévi-Strauss, as luzes e os instrumentos das trevas: sobre a moralidade selvagem ${ }^{1}$
}

\author{
Márnio Teixeira-Pinto
}

Universidade Federal de Santa Catarina, Florianópolis, Brasil

E-mail:marnio.t.pinto@gmail.com 


\section{Resumo}

A partir de algumas formulações de Lévi-Strauss relativas à "moral", este artigo propõe um lugar que o tema de uma "moralidade ameríndia" pode ter na antropologia. Algumas passagens famosas em Do mel às cinzas são tomadas como indícios dessa análise possível sobre moralidade. Ao final, aspectos importantes de certas práticas tradicionais dos índios Arara (Karib, Pará) são descritos como evidências de uma "moralidade selvagem" — uma moralidade que, expressa sob a forma de parcerias, privilegia mecanismos de disjunção e o caráter relacional e excêntrico dos modos de atuação como condição para o "estar-no-mundo".

Palavras-chave: Moralidade ameríndia. Antropologia da moral. Índios Arara. Lévi-Strauss.
Abstract

Based on some of Lévi-Strauss' formulations regarding the "moral", this article proposes a place that an "amerindian morality" may have in anthropology. Some famous passages from From Honey to Ashes are taken as evidence of this possible analysis of morality. In the end, important aspects of certain traditional practices among the Arara (Carib, Pará) are described as evidence of a "savage morality" - - a morality that, expressed in the form of partnerships, focuses on mechanisms of disjunction and on the relational and eccentric forms of activity as a condition of "being-in-the-world".

Keywords: Amerindian morality. Moral anthropology. Arara Indians. Lévi-Strauss.

ILHA

volume 11 - número 2 


\section{Lévi-Strauss e a "moral"}

A crição do que poderíamos identificar como uma preocupação com a "moral": em um lado, o maior certamente, ela é um tema talvez central dos mitos, aos quais inclusive dedica uma longa parte n'A origem dos modos à mesa (Lévi-Strauss, 2006); em outro lado quiçá periférico, menor, menos intenso ou, quem sabe, apenas transversal, mas nem por isso de importância secundária para o espírito da obra -, a "moral" surge tematizada como um dos convites que a antropologia faz ao nosso pensamento. A relação entre essas duas inscrições - a "moral" como um tema interior a ser descortinado nos mitos e a "moral" como um dos modos ou planos de reflexão que a antropologia autorizaria - nem sempre é muito clara. Para o argumento que pretendo desenvolver aqui é importante deixar essa relação um pouco mais evidente.

Num texto originalmente publicado em 1960, Lévi-Strauss afirmava:

[...] a etnologia, se permanece fiel a todas as suas tradições, contribuirá possivelmente a mostrar o caminho que conduz a um humanismo concreto, fundado sobre a prática científica cotidiana e à qual a reflexão moral permanecerá aliada irremediavelmente (1975, p. 23).

Creio ser prudente considerar como apenas um pouco mais do que retórica a "fidelidade" às tradições que Lévi-Strauss parece propor, pois a antropologia (a "etnologia", na expressão de praxe) que ali se apresenta é aquela que se produziu por dentro do desenho conceitual traçado pelo arco que vai da descoberta da América às 
teorias evolucionistas, de tal forma que nela confluem as "aspirações da ciência, da filosofia e da história" e sobre a qual ele mesmo afirmava: "aprisionada por tantos laços, [a antropologia] não romperá nenhum deles sem algum pesar" (Lévi-Strauss, 1975, p. 22). Ora, sabe-se que Lévi-Strauss, ele mesmo, alinhou-se àqueles que pesar algum demonstraram por ter rompido alguns dos laços com os quais a "ciência, a filosofia e a história" atavam a antropologia, submetendo-a aos limites de certos procedimentos analíticos que ela, ou melhor, a antropologia de Lévi-Strauss, teria justamente a tarefa de subverter e alargar.

De todo modo, o que importa notar inicialmente é a sugestão de que o chamamento a uma "reflexão moral" seria já parte integrante da antropologia de Lévi-Strauss, cujo projeto ele descreve naquele texto. Mas seria também esse chamado apenas mais um artifício retórico? Olhemos por um instante, e mesmo que provisoriamente, essa questão de saber como e onde Lévi-Strauss teria atendido a esse chamado que ele mesmo identifica como "irremediavelmente ligado" à antropologia.

Nas páginas finais d'A origem dos modos à mesa, há uma passagem reveladora:

Os dois primeiros volumes desta obra nos permitiram isolar a lógica secreta que guia o pensamento mítico, sob seu duplo aspecto de lógica das qualidades e de lógica das formas. Constatamos agora que a mitologia também encerra uma moral, porém infelizmente mais afastada da nossa do que sua lógica o é de nossa lógica. Se a origem dos modos à mesa e, para falar de modo mais geral, do decoro, se encontra, como julgamos haver mostrado, numa deferência para com o mundo, cuja civilidade consiste, precisamente, em respeitar as obrigações, segue-se que a moral imanente dos mitos vai no sentido contrário da que professamos atualmente. Em todo caso, ela nos ensina que uma fórmula de que fizemos tanto caso, como o inferno são os outros não constitui uma proposição filosófica, e sim um testemunho etnográfico sobre uma determinada civilização. Pois fomos habituados desde a infância a temer a impureza de fora. 
Quando proclamam, ao contrário, que o inferno somos nós mesmos, os povos selvagens dão uma lição de modéstia que gostaríamos de crer que ainda somos capazes de escutar. Neste século em que o homem teima em destruir inumeráveis formas de vida, depois de tantas sociedades cuja riqueza e diversidade constituíam desde tempos imemoriais seu maior patrimônio, nunca, com certeza, nunca foi mais necessário dizer, como o fazem os mitos que um humanismo bem ordenado não começa por si mesmo. Coloca o mundo antes da vida, a vida antes do homem, o respeito pelos outros seres antes do amor-próprio. E que mesmo uma estadia de um ou dois milhões de anos nesta terra já que de todo modo há um dia de acabar não pode servir de desculpa para uma espécie qualquer, mesmo a nossa, dela se apropriar como coisa e se comportar sem pudor ou moderação (Lévi-Strauss, 2006, p. 459-460).

Mesmo deixando de lado a evidente provocação ao filósofo com quem já se havia entretido em textos anteriores, não é exagerado sublinhar a relação nítida de oposição apontada por Lévi-Strauss entre tudo o que, nas análises precedentes, identificara como a "moral dos mitos" e uma "moral nossa", ironicamente sintetizada com picardia na famosa expressão daquele filósofo de que "o inferno são os outros". A questão é que, levando em conta o que havia no texto de 1960, essa comparação, e a afirmação do enorme afastamento entre ambas as "morais", é mais do que um simples contraponto elencado "a bem do argumento": é justamente o que estaria "irremediavelmente ligado" ao "humanismo concreto", cujo caminho a antropologia poderia ajudar a demarcar - isto é, uma "reflexão moral", e não apenas uma eventual "descrição da moral", tal como emanaria do interior dos mitos. ${ }^{2}$ Essa é uma primeira constatação importante.

De outro lado, talvez mais do que uma "descrição" propriamente dita, o que Lévi-Strauss propõe fazer nos mitos em relação à "moral" seja uma espécie de "extração", justo porque havia demonstrado a presença ali, subjacente, de uma espécie de "moral imanente": mais um procedimento de evidenciar, de pôr às claras algo que já estaria ali contido do que o de saber de que modo e por quais meios uma "moral" decorreria dos mitos e transbordá-los-ia em outras direções. Há, neles, repito, uma moral imanente. 
Não me parece necessário aqui perder tempo com o modo como os mitos operam, pois é disso que trata boa parte da obra de LéviStrauss. O que interessa aqui é a questão relativa ao conteúdo mesmo do que há de "moral" na imanência aos mitos - a segunda daquelas inscrições da "moral" identificáveis ao longo da obra de LéviStrauss.

\section{Da moral dos mitos aos instrumentos das trevas}

Num perspicaz artigo, Sztutman faz o interessante exercício de “extrair das Mitológicas de Claude Lévi-Strauss uma ética e uma filosofia política [...] na relação, estabelecida pelos ameríndios, entre os episódios concebidos no mito e aqueles vividos na história" (2009, p. 296). Valendo-se de uma relação traçada entre o final d'A origem dos modos à mesa e os argumentos centrais da História de Lince (Lévi-Strauss, 1993), Sztutman, dentre outras coisas notáveis, deixa mais uma vez salientada a base fundamental do pensamento ameríndio, posta sobre um princípio de "recusa à identidade".

Há, porém, outro nível nos argumentos de Lévi-Strauss sobre os mitos do qual talvez se possa igualmente extrair algo de interessante sobre sua "moral", um nível que não contradiz seu evidenciamento histórico, mas adiciona outra dimensão no quadro de suas possibilidades de expressão.

Acrescentemos ao princípio da "recusa à identidade" o igual horror às "indistinções" ou ao princípio tênue do cromatismo, tão bem demonstrado ao longo das Mitológicas, e podemos ter outro nível interessante de acesso a algo sobre a "moral dos mitos". É exemplar nesse sentido uma clássica passagem d'O cru e o cozido:

É como se o pensamento sul-americano, decididamente pessimista por sua inspiração, diatônico por sua orientação, atribuísse ao cromatismo uma espécie de maleficência original, tal que os grandes intervalos, indispensáveis na cultura para que ela exista, e na natureza, para que o homem possa pensá-la, só possam resultar da autodestruição de um contínuo primitivo, cuja força ainda se faz sentir nos raros pontos em que sobreviveu [...] (Lévi-Strauss, 2004b, p. 321). 
Retenhamos a ideia da "maleficência original" associada ao cromatismo. Ora, é sob esse mesmo registro negativo que, em Do mel às cinzas (2004a), Lévi-Strauss trata das "conjunções perigosas" entre o céu e a terra, cuja conotação caberia justamente à utilização cíclica daqueles "instrumentos das trevas" tão bem descritos e analisados na sua quarta parte: "Finalmente, se os instrumentos das trevas podem conotar a conjunção entre o dia e a noite e também entre os sexos, já sabemos que eles conotam a união entre o céu e a terra" (Lévi-Strauss, 2004a, p. 396).

Temos então, sob um mesmo registro negativo, as uniões, o cromatismo e as conjunções. E sabemos todos também que são os "afastamentos diferenciais" entre os termos, entre os elementos de que os mitos tratam o que ocupa o lugar do polo positivo. Nenhuma novidade até então, apenas uma constatação, de muito já feita e refeita: é justo nesse intervalo, delimitado por aquela "recusa à identidade" e por esse "horror" às uniões, às conjunções e ao cromatismo - o temor à falta de clareza, às indistinções e à perda dos "afastamentos diferenciais" -, que Lévi-Strauss demarcava o lugar da "moral imanente dos mitos".

Que dessas mesmas marcas do pensamento ameríndio surja outra possibilidade de tratarmos a questão da "moral" é o que caberia estabelecer, e do modo mais claro possível.

A preferência ameríndia pelas distâncias bem marcadas, pelas oposições "claras e distintas", identificada por Lévi-Strauss ao longo das Mitológicas, é coisa bastante bem firmada. É, entretanto, também uma imagem que, para alguns, expressaria (perigosamente, dir-seia) uma raiz iluminista do pensamento lévi-straussiano, abrindo a questão sobre o quanto isso expressaria igualmente, de jure e de facto, o regime de pensamento com o qual Lévi-Strauss se defrontava nas Mitológicas. É evidente que aquele arco conceitual que se inicia na descoberta da América a que se refere Lévi-Strauss no texto de 1960, e no interior do qual ele localiza a tradição da antropologia, pode, com algum cuidado, receber o nome que a ele se reservou. Trata-se, sim, do Iluminismo. E se tomarmos isso (que hoje muitas vezes mais parece uma acusação) o mais próximo possível do sentido que a ele 
reservou Foucault - isto é, considerando as Luzes não como um esforço histórico filosófico pelo estabelecimento das condições para uma definitiva "analítica da verdade", mas como o que ele, Foucault, preferia chamar de uma "ontologia do presente", um "pensamento crítico que tomará a forma de uma [...] ontologia da atualidade" (1984, p. 112) - e lembrarmos que Lévi-Strauss não recusa para a antropologia (também) a tarefa de uma reflexão moral, que vimos incluir justamente a apreciação crítica ao "tempo presente" posta à luz pelas revelações trazidas pela moral imanente dos mitos ameríndios, não haverá qualquer dificuldade em identificar nos passos de Lévi-Strauss algo de realmente fundamental no projeto das Luzes - passos seguidos, de fato, por entre pontos e coordenadas de sua própria relação com a "filosofia".

De toda maneira, a questão das aproximações singulares entre a filosofia moderna e "essas narrativas estranhas" (Lévi-Strauss, 2004a, p. 285) reveladas pelos mitos ameríndios foi diretamente tratada por Lévi-Strauss, de um modo que nos interessa recuperar. Dizia ele (por exemplo):

[...] é com o nascimento de uma economia neolítica, acarretando a multiplicação dos povos e a diversificação das línguas e dos costumes (M90), que surgem, segundo os mitos, as primeiras dificuldades da vida social, resultantes do crescimento da população e de uma composição de grupos familiares mais aventurosa do que a bela simplicidade dos modelos poderia conceber. Há dois séculos, em seu Discurso sobre a origem da desigualdade, era exatamente isso que Rousseau dizia e chamamos muitas vezes a atenção para essas visões profundas e injustamente desacreditadas. O testemunho implícito dos índios sulamericanos, tal como o extraímos de seus mitos, certamente não possui autoridade para restituir a Rousseau o lugar que lhe cabe.

No entanto, além de tal testemunho aproximar singularmente da filosofia moderna essas narrativas estranhas, nas quais, baseando-nos em sua aparência, nem pensaríamos em procurar lições tão elevadas, seria um equívoco esquecer que, quando o homem, ao raciocinar sobre si mesmo, se vê restringido a formular as mesmas

\section{ILHA}

volume 11 - número 2 
suposições - apesar das circunstâncias extraordinariamente dessemelhantes nas quais se exerce sua reflexão - é grande a possibilidade de que esta convergência, várias vezes repetida, de um pensamento e de um objeto que é também o sujeito deste pensamento desvende algum aspecto essencial, senão da história do homem, pelo menos de sua natureza, à qual sua história está ligada. Neste sentido, a diversidade dos caminhos que conduziram Rousseau conscientemente - e os índios americanos inconscientemente - a fazerem as mesmas especulações sobre um passado muito distante, não prova nada, sem dúvida, em relação a este passado, mas prova muito em relação ao homem (Lévi-Strauss, 2004a, p. 284-285).

A influência de Rousseau em Lévi-Strauss é outro dos lugarescomuns, e aqui também há pouco a acrescentar³ que não seja o de enfatizar o quanto possível é a ideia central da equivalência essencial entre os "caminhos que conduziram Rousseau [...] e os índios americanos". Relembremos, porém, que, além da passagem acima, que propõe a devida simetria entre as reflexões propostas pelas "narrativas estranhas" da mitologia e a "filosofia moderna" - mesmo que guardada a ressalva do caráter inconsciente de umas em contraponto ao caráter consciente da outra -, o verdadeiro elogio a Rousseau está alhures, no artigo que lhe atribui a derradeira "fundação das ciências humanas". Ali, Lévi-Strauss encerra sua argumentação de modo veemente, quase inflamado:

E se lhe concedemos um lugar à parte entre as grandes produções do gênio humano, é porque seu autor não só descobriu, com a identificação, o verdadeiro princípio das ciências humanas e o único fundamento possível da moral; com sua obra ele nos restituiu também o ardor há dois séculos e para sempre fervente neste cadinho onde se unem seres que o amor-próprio dos políticos e dos filósofos se empenha, por toda a parte, em tornar incompatíveis: o eu e o outro, minha sociedade e as outras sociedades, a natureza e a cultura, o sensível e o racional, a humanidade e a vida (Lévi-Strauss, 1976, p. 51).

Note-se outra vez, agora a partir da atribuição desse lugar sempar a Rousseau, a equação sugerida entre o "princípio das ciências

\section{ILHA}

volume 11 - número 2 
humanas" e "o [único] fundamento possível da moral", o que de novo evocaria o espírito do texto de $1960 .{ }^{4}$ Mas aqui a precisão é cirúrgica: a noção rousseauniana de "identificação" é o que se afirma como o eixo básico, fundamental, em torno do qual tanto as ciências humanas quanto a moral deveriam movimentar-se. Sabe-se que essa noção de "identificação" trazida juntamente com uma "recusa obstinada da identificação consigo mesmo" - e que não pode, por isso mesmo, se equiparar a qualquer ideia de (con)fusão - ocupa planos bastante variados nos muitos textos de Rousseau (sempre segundo Lévi-Strauss), servindo, dentre outras coisas, até como fundo de um primeiro estágio na reconstrução hipotética do processo de “origem das línguas".

O "eu" e o "outro" - eis a chave geral: a percepção implícita de uma profunda equivalência entre os seres. ${ }^{5}$ Mas o que interessa reconhecer aqui é que essa "identificação" é, ela mesma, produto de uma espécie de "disjunção", uma vez que se recusa, na saída, à "identificação consigo mesma".

De posse disso, é preciso voltar um passo atrás para reencontrar o princípio de nosso argumento.

O caso é que essa relação de, digamos, "identificação disjuntiva" entre "eu" e "outro" vem a ser também aquela que caracteriza o crucial do pensamento ameríndio, tal como extraída nas Mitológicas, e servia justamente de demarcação para a "moral imanente dos mitos". Eis então aqui a tese que quero defender: essa forma disjuntiva com que preferem pensar, no geral, as relações, todas e quaisquer relações, pode bem ser encarada como uma pista para darmos outra direção a algumas questões relativas ao campo da "moral", questões que perpassam, embutidas, implícitas, subjacentes, várias dimensões da vida social de muitos povos indígenas que nos acostumamos a tratar apenas segundo outros rótulos.

Ainda que não haja condições de mais detalhamentos, as etnografias disponíveis, recentes e antigas, estão repletas de descrições sobre tais "disjunções", seja entre planos da cosmologia, seja em modos de relações transespecíficas ou na sociologia nativa. Dadas as limitações, gostaria de prender-me apenas a um desses planos 
que considero estratégico para a demonstração desta tese, ou melhor, desta hipótese de que há, na obra de Lévi-Strauss, elementos interessantes para dar forma ao enfrentamento de questões relativas à "moralidade" mesmo que fora, ou além, de sua expressão na ordem dos mitos. E aqui me refiro, especialmente, àquele plano no qual os "instrumentos das trevas" jogavam um papel fundamental nas análises de Lévi-Strauss. Com o perdão do trocadilho pobre, muito pobre!, gostaria de sugerir como o esquema lévi-straussiano das trevas e das disjunções pode ajudar a pôr um pouco de luz sobre aspectos da moralidade que se ocultam por detrás de outras ordens que nos são, por história e tradição disciplinar, mais comumente evidentes para a descrição e a análise antropológicas.

\section{Das trevas à sociocosmologia}

Alguns dados etnográficos, mesmo que apresentados aqui de modo fragmentário e descontextualizado dadas as justificadas limitações, são necessários para que eu possa demonstrar ao menos a viabilidade da hipótese que venho avançando. São dois conjuntos de dados que gostaria de enumerar. Mesmo que desnecessário a um eventual especialista em etnologia amazônica, devo deixar claro, de partida, que em sua maior parte os dados que trago têm uma notável recorrência em todo o continente, e se deixo de apontá-la caso a caso e ponto a ponto é tanto porque tornaria essa apresentação ainda mais enfadonha quanto porque essa é a exata matéria de um trabalho mais longo a que venho me dedicando há algum tempo. Fica, porém, o registro de que o povo do qual trago dados e considerações está longe de ter qualquer estatuto excepcional, o que evidentemente não quer dizer que não possa ter, num ou noutro aspecto, levado mais longe ou mesmo para outras direções alguns dos problemas comuns a outros povos.

O povo a que me refiro são os Arara - Karib, habitantes da margem esquerda no Rio Iriri, afluente esquerdo do Xingu, nas cercanias da cidade de Altamira, no Pará -, com os quais convivi de forma intermitente entre os anos de 1987 e 1994, com rápidas e pequenas 
visitas posteriores. Os conjuntos de dados a que me remeterei são relativos, de um lado, ao plano dos ciclos rituais associados às longas caçadas das estações secas e, de outro, às operações que os Arara realizam sobre aquela espécie de fundo comum amazônico que são as diversas formas de relações e de agentes em relação.

Como entre inúmeros povos indígenas amazônicos, para os Arara também havia um mundo original, primevo, cuja grande marca era a de uma ampla e irrestrita indistinção. Não apenas os seres todos (ou quase) ${ }^{6}$ se misturavam, como também os planos todos se misturavam - para melhor dizer: havia apenas um plano realmente habitável, que era como uma "casca" no céu, no qual boa parte do seres convivia; do lado de "fora" dessa casca era tudo água. O fato crucial é que houve uma briga, uma enorme briga que terminou por estender-se a toda a gama de seres, e esse plano, o assoalho que dava suporte à vida, rompeu-se, caindo das alturas celestes e dando lugar aos domínios agora separados do céu, da terra e da água (que, após o cataclismo, é mais parte que se mistura a terra do que um domínio que efetivamente dela se separe).

Há um grande (e complexo) sistema ritual Arara que se refere a, ou que toma como condição essa descrição do mundo atual tal como criado pela "grande briga" inaugural. Esse sistema ritual pode ser bem sintetizado através de um modelo muito esquemático:

1. os ritos são associados a grandes caçadas feitas por determinado grupo de caçadores que permanece longos períodos acampado na floresta;

2. cada caçada é oferecida, em festa, a outro grupo, que então servirá de anfitrião quando do retorno dos caçadores;

3. toda e qualquer caçada depende tanto de artifícios xamânicos junto a seres espirituais que são os verdadeiros "donos" ${ }^{\prime 7} \mathrm{e}$ protetores das espécies animais caçadas quanto de técnicas de caça que afirmam o caráter de "sujeito" de cada animal (como espécie e como espécime) a ser caçado;

4. aqueles que aguardam, na aldeia, pelo retorno dos caçadores devem executar uma longa sequência musical, em aerofones 
especialmente fabricados para a ocasião, cujos temas melódicos são associados às espécies animais caçadas; ${ }^{8}$

5. os caçadores, quando retornam à aldeia, devem vir "disfarçados", valendo-se de uma vestimenta ritual composta de perucas de palha, saias de penas de mutum, peças de vestuário na cor vermelha (antes da presença das roupas industriais, parte dos corpos era pintada com urucum); e

6. além do "disfarce ritual", ou talvez mesmo como parte dele," os caçadores realizam, em algazarra e pantomima, uma invasão da aldeia onde os anfitriões os esperam executando as melodias previstas e as mulheres os aguardam com recipientes plenos de uma cerveja fermentada a partir da farinha de macaxeira com o fim precípuo e expresso de "trocá-la" pelas carnes que os caçadores trazem.

Esse é um esquema sintético de um modelo do sistema ritual Arara que, como se nota, está montado a partir da prática das caçadas. Lembremos então que há o fato geral de que, como para vários outros povos indígenas, a caça é, também para os Arara, atividade tensa, séria, repleta de riscos de toda ordem. Em sua dimensão cinegética e predatória, a caça amazônica é bastante bem estudada, e não creio que haja algo sério a retificar. Quero aqui mencionar apenas um aspecto implicado em um desses riscos que são os perigos impostos pela eventual proximidade excessiva entre os envolvidos na caça - e aqui não estou me referindo apenas aos, digamos, humanos "propriamente ditos". Animais e outros seres, espirituais, estão todos incluídos aí, posto sabermos de sua ontologia, de seu estatuto e de sua importância nas sociocosmologias amazônicas (ver, obrigatoriamente, Lima, 1996; Viveiros de Castro, 1996, 2002a, 2002b).

Disse há pouco que toda e qualquer caçada depende tanto de artifícios xamânicos junto a seres espirituais que são os verdadeiros "donos" e protetores das espécies animais caçadas. Examinemos em que consiste esse artifício.

Cabe sempre a algum xamã ${ }^{10}$ a existência de animais livres nas matas. É uma intercessão sua junto aos "donos da caça" que os têm sob sua guarda e proteção, o que garante a soltura dos bichos. Um xamã vai à floresta munido de um pequeno porrete e, percutindo 
vigorosamente contra o tronco das árvores, pede (ou "manda" e "exi-

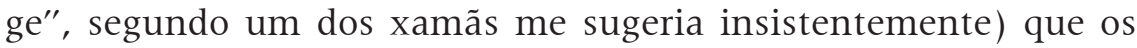
"donos" dos animais os libere nas matas. Aqui, outra vez, podemos facilmente reencontrar o tema das "trevas", mesmo que com a peculiaridade da

estranha analogia entre os meios empregados pelo chamado percutido nos mitos sul-americanos - cabaça ou tronco de árvore nos quais se bate, bastões que se entrechocam, chicote - e um complexo litúrgico do Velho Mundo, conhecido sob o nome de instrumentos das trevas (LéviStrauss, 2004a, p. 379).

Em que consiste esse pedido, essa ordem ou exigência do xamã junto aos "donos dos animais"? Há um enunciado explícito na fala do xamã que nos permite compreender o estatuto que têm, a essa altura, o tema das "trevas" e sua passagem para o espaço circunscrito por uma moralidade. Seja como pedido, ordem ou exigência, o xamã enuncia o seguinte: "Eu tenho filhotes para criar. Eu não tenho mais nenhum filhote para criar. Dê-me filhotes para criar!"11

O interessante da fórmula é a intenção expressa de que os "donos dos animais" liberem filhotes para serem criados. Anunciada na expressão nativa iamït, a criação de animais é, de fato, uma instituição comum entre os Arara e bastante geral no continente, ainda que traga em si o paradoxo de que os modos assumidos por essa criação de animais não tenha resultado em nenhuma forma forte de domesticação dos animais (como, por exemplo, teria ocorrido na Melanésia). Trata-se de fenômeno sobre o qual muitas pesquisas ainda se hão de fazer. Não há aqui, porém, espaço para elaborar melhor a questão nem aprofundar a própria descrição do que em torno dele os Arara construíram.

O que concretamente importa aqui é apenas o estatuto do pedido dos xamãs: "filhotes para criar" é do que se trata. Mas eis que desse pedido do xamã - para que tenha filhotes "para criar", insisto - surge a própria condição de toda caça: é que a intercessão dos xamãs povoa as matas... que os caçadores então percorrem atrás de presas. Mesmo que ao pedido do xamã se siga a decorrente e forte 
interdição de que ele, em lugar de tomar das matas os filhotes para criar, os tome como eventuais presas, não há impedimento algum para que outros humanos o façam: desse modo, o que interdita a caça a um (o xamã que pede filhotes para criação) é, no mesmo instante, o que permite a caça de todos os demais (que nada pediram e então a nada estão interditados).

Entre o pedido do xamã e os atos de predação dos caçadores se instaura um intervalo, um hiato, uma lacuna, um espaço "vazio", mas que é tanto objetivo - porque define a possibilidade da caçada efetiva - quanto intersubjetivo - porque se estabelece entre conjuntos de sujeitos distintos: entre o xamã e os oto, espíritos-donos-dacaça, entre os caçadores e o xamã, mas, sobretudo, entre os humanos e os oto. Voltarei a esse ponto adiante, mas quero deixar anotado neste momento que a relação entre os xamãs e os oto vem sinalizada com o código acústico da percussão de seu porrete nos trocos das árvores - sinal sonoro de que haverá, ali, aproximação, contato, junção entre os planos do humano e o do espírito-dono-da-caça... um anúncio do tema das "trevas", portanto.

A evocação sonora das "trevas" nos permite também afirmar que aquele espaço "vazio", o intervalo perceptível entre o pedido do xamã - e a consequente interdição de que o xamã venha a matar, a qualquer pretexto, os animais pedidos - e o fato real de que os caçadores não estão sujeitos a qualquer interdição e, por isso, tiram proveito do pedido do xamã para caçar suas presas, é, nesse sentido, a reimposição de uma fratura no contínuo entre os planos que havia sido reintroduzido no mundo pela relação do xamã com os oto e que era sinalizado por aquele "porrete das trevas" com que o xamã anuncia a relação entre eles. Note-se, igualmente, que essa fratura, essa descontinuidade (re)imposta ao mundo vem marcada como uma espécie de "traição global" entre os humanos e os espíritos-donosda-caça, oculta pela sobreposição de diferentes relações: entre o xamã e os oto (entre quem se dá o pedido e se estabelece a interdição); entre os humanos e os animais caçados (cuja relação depende do ato do xamã, mas em cuja direção a interdição não se estende); entre o xamã e os demais humanos (para quem se dirige a propiciação da 
caça); e, finalmente, entre os oto e suas espécies protegidas. É que aquilo que o xamã pede se torna interdito, mas os demais podem matar sem restrição... se trata de um estratagema, um ardil de que os humanos se valem de uma suspensão do xamã de seu papel de caçador (uma contrapartida da interdição que incidirá sobre si) para que os demais possam caçar. $\mathrm{O}$ ardil se completa com a constatação de que, entre os Arara e para as grandes caçadas coletivas, vale o imperativo de que as carnes de um animal abatido devem ser oferecidas justamente àqueles que não mataram o animal. Eis o outro interdito que completa o estratagema: se quem pediu aos oto não mata e quem mata não come... quem pediu pode, enfim, comer, sem que haja aí qualquer contravenção!

O ponto a notar é que o tema das "trevas" introduzido nessa forma de propiciação da caça revela que tudo se dá justo na conjunção de dois planos - o dos humanos e o dos oto - e que o estratagema, o ardil de que os humanos se valem é que o reintroduz na disjunção necessária entre os planos, separando outra vez os humanos em sua situação de vida dependente da caça e os oto em sua condição de protetores das espécies animais. A uma reaproximação, uma nova separação; a uma junção, uma disjunção.

Voltemos para as caçadas que tal estratagema é a garantia de suas condições de possibilidade.

Dependendo do trânsito constante pelas matas, o procurar e o abater a caça implica também proximidades perigosas e sujeita os caçadores a incontáveis riscos. Ora, são evidentemente esses os riscos expressos por aquela codificação acústica da "sinfonia selvagem" que o plano sonoro-musical dos ritos traz como uma de suas etapas fundamentais. Como a floresta é uma espécie de "resto" cosmológico, parcela caída do que era o plano habitável original do mundo primevo, toda caça implica também uma espécie de reaproximação entre planos que, nominal e originalmente, deveriam estar separados. Esse é o dado principal que aproxima todo esse modelo ritual das caçadas daquele esquema das "trevas" de que trata Lévi-Strauss na quarta parte de Do mel às cinzas. Tudo ali expressa essa aproximação e seus riscos: as melodias, que são como um retorno à possibilidade de co- 
municação com os "donos" dos animais; o disfarce dos caçadores e toda a algazarra que impõem à aldeia quando de seu retorno, que são como notícia da (re)junção momentânea de seres distintos. Mas é como se, num passe, o rito se resolvesse a partir da troca de bebida produzida pelo grupo anfitrião pela carne trazida pelo grupo dos caçadores: com ela, encerram-se as músicas e a algazarra, como se o perigo expresso pela perambulação na floresta e pelo desejo de abate dos animais estivesse, pelo menos provisoriamente, controlado. Se houve, como parte de tudo, o perigo da aproximação à floresta e aos seres que por ali circulam - que se poderia bem notar que supõe também um modo de "identificação" com os animais pela admissão de seu caráter de sujeito, incluindo as formas de comunicação com os "guardiões" dos animais -, tudo parece se resolver numa espécie de retorno à diferenciação entre os que foram caçadores e os que foram caçados, numa resseparação entre os humanos ali e os espíritos e animais acolá. O fato de que resseparação se opera sobre um “o resíduo de um contínuo devastado" (Lévi-Strauss, 2004a, p. 321) é o que se justamente evidencia em todas as situações em que o tema das "trevas" se faz novamente presente. São elas, as "trevas", o símbolo de uma rejunção momentânea, necessária apenas ao restabelecimento das separações e das diferenciações.

Note-se, portanto, que o modelo ritual associado às caçadas supõe, em várias de suas dimensões e de modos relativamente diferentes entre si, um esquema que inclui modos de aproximação, identificação e diferenciação. E isso é o que importa para a continuação do argumento na direção daquilo que, decorrendo das possibilidades dadas pelo esquema (mito)lógico das "trevas" e pelo modelo dos ritos das grandes caçadas, é parte do que vi ocorrer entre os Arara.

\section{A sociocosmologia e a moralidade das trevas}

Seria razoavelmente apropriado dizer que, de tão cheio de tensões, riscos e perigos, todo o ato de caçar para os Arara pede mais do que um simples caçador. Não é a única dimensão de sua vida social em que esse pedir mais de "um" para uma mesma atividade ocorre, mas as parcerias estabelecidas para e durante as caçadas têm algu- 
mas características próprias que bem servirão para demonstrar certos efeitos.

Em primeiro lugar, é preciso deixar bem estabelecido o caráter "não utilitário" das parcerias de caça. Tanto do ponto de visto técnico quanto em relação às habilidades previstas para que a caça se realize, as parcerias seriam completamente desnecessárias, pois não há homem jovem ou já plenamente adulto que desconheça aquilo que de fundamental pede uma caçada. Há, certamente, uns mais especialistas em tais ou quais aspectos envolvidos na procura dos rastros e dos sinais e no abate das presas, mas no geral todo e qualquer homem é plenamente capaz de sair sozinho à caça - e de fato o faz no cotidiano, no ordinário da vida, na busca do sustento de si e de sua família. Não se trata, portanto, de um imperativo técnico aquilo que chama a uma parceria para as longas caçadas realizadas nas estações secas e que terão, como seu prolongamento, os ritos cujo modelo esquemático básico foi apresentado.

Tais relações de parceria, que entre os Arara se proliferam quase ad infinitum, ${ }^{12}$ colocam de fato alguns problemas comparativos. Não é possível entrar aqui na discussão sobre qual imagem melhor descreveria o princípio de "toda relação" para vários povos indígenas se a "inimizade" ou a "amizade" - e que certamente mereceria um tratamento mais completo e exaustivo. ${ }^{13}$ Sem entrar na questão do estatuto dessas parcerias ou formas de "amizade", é preciso aqui demarcar com clareza o lugar que elas ocupariam no pensamento ameríndio (no dos Arara, ao menos, para os fins desta apresentação): o que um pensamento marcado pela ênfase na disjunção, na separação, na descontinuidade afirma quando estabelece para certos fins uma ação a dois, o agir em pares como um ideal? Claro, há sempre o apelo a um dualismo, digamos, "genérico" pelo qual esse "fazer a dois" seria apenas a passagem imediata ao ato de um princípio do pensamento. Essa é uma afirmação inteiramente sustentável até mesmo pelo simples fato de que os parceiros Arara são designados, na maior parte das vezes, ${ }^{14}$ de "outros, uns dos outros": ïbirinda, meu "outro", é como devo chamar aquele que me acompanha em parceria. Inteiramente sustentável, mas absolutamente incompleta - é o que proponho. 
Penso que as coisas podem não ser assim tão simples. E um rápido olhar sobre o que se passa entre os parceiros Arara pode ajudar a iluminar a questão. Em termos gerais e, tal como para os modelos dos ritos das caçadas coletivas, igualmente esquemáticos, as parcerias Arara funcionam segundo um padrão lógico que pode ser resumido a alguns elementos principais:

1. uma vez estabelecida, uma parceria perdura e se mantém inclusive após uma eventual mudança de residência;

2. numa caçada, se um dos parceiros mata um animal, é o "outro" que deve carregar o animal abatido;

3. no retorno de uma caçada, cabe aos parceiros o mútuo cuidado contra possíveis "infestações metafísicas" ou "contágios espirituais"; e

4. no retorno de uma caçada, ao identificar entre os anfitriões um antigo parceiro, cabe a ele ser chamado para o tratamento culinário e a partilha de um animal abatido.

O que há de subjacente à lista desses elementos que descrevem o modo-padrão de atuação dos parceiros é um único princípio: a obrigação de uma espécie de "dependência" em relação ao parceiro (que, como na própria atividade de caça, não é uma dependência, a rigor, técnica) que é, no plano das relações, a imposição de um princípio que nega a possibilidade de autonomia de qualquer um dos parceiros: nem se deve agir sozinho, nem se deve agir para si mesmo. As parcerias são uma espécie de expressão de um intervalo imposto entre o indivíduo e ele mesmo. Contra a autonomia possível de qualquer um, o que as parcerias preenchem é uma espécie de "lugar vazio", ou melhor, de um espaço artificialmente criado, uma separação forjada, uma disjunção imposta à própria existência de cada um e, portanto, da existência de todos.

Em outras palavras, é como se o "agir a dois" fosse o produto necessário da impossibilidade, imposta, normativa, do "agir como um": contra o "em-si" e o "para-si". Então, aquilo que, num plano, pareceria ser simplesmente a expressão de uma desejada conjunção entre "eu e um outro" (ter e agir com e como parceiro) se revela de fato, e 
justamente, como o efeito de uma disjunção no plano de um "eu": pois o que há é o interdito quanto a se agir sozinho ou para si mesmo, sendo as parcerias aquilo que decorre dessa impossibilidade, imposta, normativa.

Então, se as parcerias Arara, mais do que de "conjunções", pareceriam efeitos de "disjunções", qualquer noção de "identificação" que vá ali a reboque das parcerias não poderia jamais significar "identidade", mas apenas "diferença". Não há "conjunção" nas parcerias, porque não deve haver "conjunção" no mundo, a não ser quando o esquema das "trevas" é posto a funcionar para que se imponha, outra vez, uma disjunção. Conjunção? Só aquela que possa ser qualificada como "disjuntiva": o que une deve ser aquilo que separa. É como se um Arara pudesse então dizer: "o que me une ao meu ïbirida, meu 'outro', meu parceiro, é aquilo que me separa de mim". Ou aquilo que ao "um" se interdita ${ }^{15}$ - base, "moral", perceba-se, para os mecanismos de uma diferenciação fundamental e que só se dá através de uma referência peremptória e, sobretudo e principalmente, "injuntiva"16 a um "outro".

Eis então o lugar onde se instalam as parcerias Arara: a imposição, no plano das relações entre os indivíduos, do princípio das disjunções necessárias à inteligibilidade do mundo, longe das "trevas" que anunciam conjunções, hoje, insuportáveis. Mais do que qualquer forma local de "identidades", parcerias Arara são simples diferenças - talvez mesmo o mecanismo mais simples das diferenças ou o mecanismo mais produtivo das diferenças mais simples.

Como se viu que todas essas operações que as parcerias definem supõem o funcionamento, em momentos e em planos distintos, daquele esquema das "trevas" e vê-se agora que elas de fato incluem um dispositivo pelo qual, a partir do funcionamento do regime das trevas, a "moral dos mitos" se desdobra em imperativos práticos para a ação, concreta e efetiva, não seria um erro afirmar: há no argumento as evidências de as "trevas" e a "moralidade" caminharem juntas no pensamento e nas práticas Arara. Saber de sua possibilidade e seu interesse comparativos é tarefa para outro momento. 


\section{Moralidade das trevas, moralidade selvagem}

Para encaminhar a conclusão desta apresentação - que não tem mais do que o sentido de propor um modo de abordagem a algumas questões relativas à moral ameríndia baseado num argumento e num modelo de análise inspirado nas Mitológicas de Lévi-Strauss -, creio ser suficiente elencar um conjunto de considerações sobre algumas consequências que as análises precedentes podem ter. Esquemáticas, sem dúvida, como muito do que foi apresentado.

Ao longo da apresentação, propus que a quarta parte de Do mel às cinzas bem poderia servir de inspiração para enfrentarmos aspectos relativos a uma possível expressão ameríndia de questões morais. Atravessando passagens bastante restritas de ideias presentes nas Mitológicas, mesmo que originadas em outros textos (como no caso do texto sobre as Fontes da etnologia), viu-se inicialmente um duplo lugar da "moral" do pensamento lévi-straussiano: uma reflexão moral como chamado da própria antropologia e o encontro de uma "moral imanente aos mitos". Ao final de nossa exposição, creio que se possa sustentar que se encontrou mais um lugar, embutido naquilo que as análises lévi-straussianas dos "instrumentos das trevas" nos servem para a compreensão de aspectos centrais da vida social e do pensamento de um povo amazônico em particular (mas que guardaria correspondências notáveis com vários outros).

Àquilo que, de questões relativas à "moral", emanaria desse novo lugar bem que se poderia chamar de "uma moralidade das trevas" que vimos determinar o "outro" como o efeito de uma renúncia, imposta, produzida, sobre um "eu", justo como o mecanismo de evitar conjunções excessivas anunciadas nas relações entre vários planos e vários agentes. A evitação das conjunções indevidas - simbolizadas pelas várias inscrições do tema das "trevas" nos fragmentos de etnografia que trouxemos aqui - e o resgate das disjunções que definem e articulam certos modos concretos de "diferença" e "alteridade" são o fundamento desse plano do qual uma "moralidade ameríndia" tira seus principais elementos: a prioridade da descontinuidade e dos mecanismos de disjunção como engrenagens que geram os modos de relação com o outro. 
Tomo então como absolutamente possível sustentar que a "linguagem das disjunções" que Lévi-Strauss traz nas Mitológicas parece muito mais apropriada a se descrever um regime moral que se estabelece bem mais como "relacional" do que através de "valores substantivos". Esse seja talvez um erro comum nas tentativas de se procurar, em nível dos "valores morais", aquilo que poderia ser generalizado para o continente, e não se encontrar mais do que uma constatação de princípios "genéricos" (que não devem ser confundidos com "gerais"), como a generosidade, a reciprocidade, o controle de si etc.

Uma ação "diferenciadora" é o que o princípio das disjunções desencadeia. Mas vimos que, no caso Arara pelo menos, a disjunção inicial tem como lugar a evitação de qualquer princípio de autonomização de um só. E é justamente por causa disso que podemos chamar essa operação de "moralidade selvagem": porque o que serve de princípio e estatuto para a relação com o "outro" não supõe qualquer artifício de se instituir, por meio de uma construção abstrata, de uma noção metafísica de "universal", que, efetivamente, tem cada indivíduo o seu eixo. Essa "moralidade selvagem", ao contrário, tem na concretude da existência de um "outro", na sua justa diferença, o eixo sobre o qual pode se estabelecer. Um "temor às trevas" - não como um suposto horror dos primitivos à escuridão ou às forças da natureza, mas como horror à perda das diferenças - faz do "outro" o princípio de uma "super-ação" que não pode implicar outra coisa senão a definição de um caráter "relacional", excêntrico, e não individual para qualquer modo de atuação dos sujeitos, como sua única escolha possível para o "estar-num-mundo-sem-trevas".

\section{Notas}

${ }^{1}$ Este texto é uma versão revista e parcialmente modificada da apresentação feita no evento comemorativo dos 100 anos de Lévi-Strauss, realizado na UFSC em 2008. Nesta versão, guardaram-se o tom oral da apresentação original e o caráter preliminar e, por vezes, ligeiro de algumas análises. Com isso em mente, continuaria afirmando o geral do que vai aqui, que é parcela de um projeto sobre a natureza e as formas de uma moralidade ameríndia que ainda cobra seus principais resultados.

${ }^{2}$ Vários escritos de Lévi-Strauss são eivados de considerações comparativas dessa ordem, demonstrando que ele, de fato, jamais se teria furtado àquele mandato

\section{ILHA}


expresso no texto de 1960 e que, possivelmente, teria tido bem mais o papel de anunciar e deixar explícito de antemão algo que se anunciava realizável adiante.

${ }^{3}$ Gostaria, porém, de insistir sobre uma única referência: o belíssimo texto de Bento Prado Jr. (2008) no qual se evidencia o papel que Lévi-Strauss atribuía a Rousseau de ter produzido uma revolução na filosofia, demolindo suas pretensões universalistas e metafísicas, e antecipado os procedimentos da antropologia, que virá a exprimir a fórmula de que "toda a humanidade é local [...] e a humanidade só se encontra no sistema de diferenças" (Prado Jr., 2008, p. 320).

${ }^{4} \mathrm{O}$ artigo sobre Rousseau, publicado apenas em 1973 na Antropologia estrutural dois, se origina de fato em discurso feito ainda em 1962.

${ }^{5}$ Vale a pena relembrar também que, nesses termos, Lévi-Strauss reservava à experiência etnográfica tanto a averiguação dessa fórmula quanto a "demonstração que lhe compete de que o outro é [também] um eu” (Lévi-Strauss, 1976, p. 44).

${ }^{6}$ Há na cosmologia Arara uma classe de seres cuja ontologia os coloca fora da dimensão original em que todas as demais viviam.

7"Dono" é de fato uma tradução muito apropriada para o termo nativo oto.

${ }^{8} \mathrm{O}$ que conforma aquilo que, em outro lugar, chamei de "sinfonia selvagem" e "bestiário melódico" (Teixeira-Pinto, 1997).

${ }^{9}$ Veja-se a este respeito Teixeira-Pinto (2009).

${ }^{10}$ E eles são muitos entre os Arara, o que será detalhado adiante.

${ }^{11}$ Trata-se de uma tradução aproximativa da fórmula nativa: Iamitt'pra uro. Iamït'pra tangie. Ibirinda pin!

${ }^{12}$ Às quais poderíamos certamente acrescentar as variadas formas de "amizades formais" tão bem descritas para vários povos (ver, por exemplo, Carneiro da Cunha, 1979).

${ }^{13}$ Mas pode-se consultar vários textos de Viveiros de Castro (1992, 2002a, 2002b, 2009).

${ }^{14}$ Há um tipo de parceria Arara que tem um regime simbólico e sociológico distinto, o qual implica outra forma de designação e outros modos de atuação, mas que, no geral, não contradiz alguns dos aspectos fundamentais dos tipos mais comuns de parcerias.

${ }^{15}$ É evidente a influência clastreana nesse tipo de formulação que, no entanto, tem em La Boétie um suporte fundamental (ver Chauí, 1982; Clastres, 1982; La Boétie, 1982; Lefort, 1982).

${ }^{16}$ Do verbo "injungir": impor a obrigação de, ordenar expressamente.

\section{Referências}

CARNEIRO DA CUNHA, Manuela. De amigos formais e pessoa; de companheiros, espelhos e identidades. Boletim do Museu Nacional, v. 32, p. 31 39, 1979. (Nova série Antropologia).

CHAUÍ, Marilena. Amizade, recusa do Servir. In: LA BOÉTIE, Etienne de (Ed.). Discurso da servidão voluntária. São Paulo: Brasiliense, 1982. p. 173-239.

CLASTRES, Pierre. Liberdade, mau encontro, inominável. In: LA BOÉTIE, Etienne de (Ed.). Discurso da servidão voluntária. São Paulo: Brasiliense, 1982. p. 109-123.

\section{ILHA}


FOUCAULT, Michel. O que é o Iluminismo. In: . O dossier: últimas entrevistas. Rio de Janeiro: Livraria Taurus Editora, 1984. p. 103-112. LA BOÉTIE, Etienne de. Discurso da servidão voluntária. São Paulo: Brasiliense, 1982.

LEFORT, Carlos. O nome de um. In: LA BOÉTIE, Etienne de (Ed.). Discurso da servidão voluntária. São Paulo: Brasiliense, 1982. p. 125-171.

LÉVI-STRAUSS, Claude. Las tres fuentes de la reflexión etnológica. In: LLOBERA, José Ramón (Ed.). La antropología como ciencia. Barcelona: Anagrama, 1975. p. 15-23. . Jean-Jacques Rousseau, fundador das Ciências do Homem. In: (Ed.). Antropologia estrutural dois. Rio de Janeiro: Tempo Brasileiro, 1976. p. $41-51$. . História de Lince. São Paulo: Companhia das Letras, 1993. . Do mel às cinzas. São Paulo: Cosac \& Naify, 2004a. . O cru e o cozido. São Paulo: Cosac \& Naify, $2004 \mathrm{~b}$. . A origem dos modos à mesa. São Paulo: Cosac \& Naify, 2006. LIMA, Tânia Stolze. O dois e seu múltiplo: reflexões sobre o perspectivismo em uma cosmologia tupi. Mana, Rio de Janeiro, v. 2, n. 2, p. 2 1-47, 1996.

PRADO JR., Bento. Filosofia, música e botânica: de Rousseau a Lévi-Strauss. In: _. A retórica de Rousseau e outros ensaios. São Paulo: Cosac \& Naify, 2008. p. 317-328.

SZTUTMAN, Renato. Ética e profética nas Mitológicas de Lévi-Strauss. Horizontes Antropológicos, Porto Alegre, v. 15, n. 31, p. 293-319, 2009.

TEIXEIRA-PINTO, Márnio. Ieipari: sacrifício e vida social entre os índios Arara (Caribe). São Paulo: Hucitec/Anpocs; Curitiba, PR: Ed. UFPR, 1997. . Sobre saias, perucas e apitos: disfarce ritual e sociabilidade humana entre os Arara (Karib, Pará). In: CAVALCANTI GONÇALVES, José Reinaldo (Ed.). As festas e os dias: ritos e sociabilidades festivas. Rio de Janeiro: Contra Capa, 2009. p. 197-206.

VIVEIROS DE CASTRO, Eduardo. From the Enemy's Point of View: Humanity and Divinity in an Amazonian Society. Chicago: University of Chicago Press, 1992.

. Os pronomes cosmológicos e o perspectivismo ameríndio. Mana, Rio de Janeiro, v. 2, n. 2, p. 115-144, 1996.

. A imanência do inimigo. In: VIVEIROS DE CASTRO, Eduardo. (Ed.). A inconstância da alma selvagem: e outros ensaios de Antropologia. São Paulo: Cosac \& Naify, 2002a. p. 181-263. 
. Perspectivismo e multinaturalismo na América indígena. In: VIVEIROS DE CASTRO, Eduardo (Ed.). A inconstância da alma selvagem: e outros ensaios de Antropologia. São Paulo: Cosac \& Naify, 2002b. p. 347-399. . Métaphysiques cannibales: lignes d'anthropologie post-structurale. Paris: Presses Universitaires de France (PUF), 2009.

Recebido em: 08/11/2010

Aceite em: 20/12/2010 